\title{
Sex and Punishment: An Examination of Sexual Consequences and the Sexual Double Standard in Teen Programming ${ }^{1}$
}

\author{
Jennifer Stevens Aubrey ${ }^{2,3}$
}

\begin{abstract}
A content analysis was conducted to examine sexual consequences on teen programming. The sample consisted of prime-time television dramas that featured characters between the ages of 12 and 22 years. Two major goals guided the study. First, the types of sexual consequences in teen programming were investigated. Results showed that emotional and social consequences far outnumbered physical consequences. Second, the portrayal of the sexual double standard was investigated. Negative consequences were more common in scenes in which female characters initiated sexual activities than in scenes in which male characters initiated sexual activities. Implications for future content analyses and media-effects research are discussed.
\end{abstract}

KEY WORDS: sex; adolescents; television; sexual stereotypes; content analysis.

Content analyses of sex on television have provided a great deal of information about the frequency and explicitness of sexual behavior and dialogue (Fernandez-Collado, Greenberg, Korzenny, \& Atkin, 1978; Franzblau, Sprafkin, \& Rubinstein, 1977; Greenberg et al., 1993; Kunkel, Cope, \& Biely, 1999; Kunkel, Cope, \& Colvin, 1996; Kunkel, Cope-Farrar, Biely, Farinola, \& Donnerstein, 2001; Sprafkin \& Silverman, 1981; Truglio, 1998; Ward, 1995), yet one contextual element of the portrayal of sexuality has not been adequately conceptualized and analyzed: the portrayal of sexual consequences. A common theme from content analyses is that sex on television is virtually free of consequences (Kunkel et al., 1996, 1999, 2001; Sprafkin \& Silverman, 1981; Truglio, 1998). For

\footnotetext{
${ }^{1}$ An earlier version of this article was presented at the 2001 meeting of Broadcast Education Association, Las Vegas, NV, and at the 2002 meeting of the International Communication Association, Seoul, Korea.

${ }^{2}$ Department of Communication Studies, The University of Michigan, Ann Arbor, Michigan.

${ }^{3}$ To whom correspondence should be addressed at 2020 Frieze Building,105 S. State St., Ann Arbor, Michigan 49109-1285; e-mail: stevensz@umich.edu.
}

example, Truglio (1998) found that a 1990 representative sample of 109 network television programs contained only 16 references to any form of unwanted pregnancy or STD in the entire sample.

However, researchers have typically defined sexual consequences as physical and have downplayed the more ubiquitous emotional and social consequences of sex. In biennial content analyses of primetime television shows, Kunkel et al. (1999, 2001, 2003) coded "risk or responsibility themes," defined as sexual patience (waiting until a relationship matures and both people are equally ready to engage in sex), sexual precaution (pursuing efforts to prevent AIDS, STDs, and/or unwanted pregnancy), and depiction of risks and/or negative consequences of irresponsible sexual behavior, such as unwanted pregnancy and anxiety about contracting AIDS. Two of these three themes were hinged on the definition of consequences as physical, that is, STDs and unwanted pregnancies. Kunkel et al. (2003) concluded that although risk/responsibility themes were relatively rare amid the large number of scenes with sexual talk or behavior, they had increased modestly since the 1998 sample of television programming. The percentage 
of scenes with any sexual content that mentioned risk/responsibility was 4\% in 1998 and 6\% in 2002, and the percentage of episodes with risk/responsibility themes increased from $9 \%$ in 1998 to $15 \%$ in 2002.

Although researchers have defined the negative consequences of sexuality as physical, it appears that adolescents are just as concerned with the emotional and social consequences of sex. For example, adolescents are relatively unconcerned about the physical dangers of sex and more concerned about the maintenance of their sexual reputations, about uncertainty and confusion about their bodies, and about their emotional relationships with their sexual partners (Martin, 1996). Thus, a central goal of the present study was to broaden the definition of sexual consequences to include emotional and social consequences, which were expected to be more common than physical consequences.

Another goal of this study was to investigate the possibility that the portrayal of sexuality differs by gender. According to the sexual double standard, sexual activity among young men is tolerated and encouraged, whereas for young women, sexuality is controlled, restricted, and subjected to censure if norms are violated (Jessor \& Jessor, 1975; MacCorquodale, 1989; Muehlenhard, 1988). If television targeted at adolescents perpetuates this script, men's sexuality will be seen as rewarded, and women's sexuality will be seen as punished.

One way in which the sexual double standard could be manifested on television is through the portrayal of male characters disproportionately initiating sexual activities. Kunkel et al. (2001) found that female characters were more likely to initiate physical flirting, but male characters were more likely to initiate kissing/intimate touching and sexual intercourse. When types of behaviors were collapsed, however, male and female characters initiated approximately the same number of sexual behaviors. The hypothesis that male characters will be more likely to initiate sexual activities was tested again in this study.

No research to date has examined differences in whether women or men are more likely to be portrayed as receiving sexual consequences. However, some research has shown that in general television portrayals of women's sexuality differ from those of men's sexuality. Ward (1995) found several themes that support the sexual double standard in a content analysis of the television programming most popular among adolescents. One of the most frequent messages in the programs was that men view women as sex objects and value them primarily for their physical appearance. Other messages characterized women as delimiters of sexual activities. Popular teen magazines also commonly present adolescent sexuality in accordance with the sexual double standard. In Seventeen and $Y M$, women's sexuality was associated with allure, passivity, and responsibility, whereas men's sexuality was associated with aggression and urgency (Carpenter, 1998; Durham, 1998). In Seventeen, adolescent girls were portrayed as obsessed about boys, but they were warned to be passive in interacting with boys in sexual situations (Wray \& Steele, 2002). According to Durham (1998), one of the most troubling aspects of these texts was the underlying message that discouraged women from acknowledging their sexuality; the texts focused instead on how to curb the insatiable sexual appetites of men. Certainly, structural and narrative features of magazines are qualitatively different from entertainment television. Nevertheless, the possibility that similar trends in support of the sexual double standard exist in entertainment television merits exploration. In keeping with the findings of the content analyses on television and magazines, female characters might be more likely than male characters to be portrayed as experiencing negative sexual consequences, and this might be the case especially when female characters are shown initiating the sexual activity. Likewise, male characters might be more likely than female characters to reap the positive outcomes of sexuality.

Exploring the sexual consequences of male and female characters is motivated by social cognitive theory (Bandura, 1994), which argues that individuals can learn how to perform behaviors from media models. The principle of vicarious reinforcement is especially useful in conceptualizing what audiences might learn from television. According to the theory, the functional value of the modeled act is communicated to audiences through the rewarding or punishing of the action. For example, when a viewer observes a model engaging in an enjoyable sexual behavior and perceives that person as rewarded in some way, the viewer will be vicariously reinforced to model that behavior (Bandura, 1994). On the other hand, a viewer will be discouraged from modeling the behavior if he or she perceives the behavior as resulting in an unrewarding or a punishing outcome. The positive or negative consequences received by the model for performing the behavior serve as cues that indicate the perceived functional value of the act 
and thus guide the viewer about the appropriateness of performing the act. Thus, it is important to discern what types of messages regarding the functional value of sexuality are presented to young television viewers because these messages can have implications for adolescent viewers' decisions to model sexual scripts on television.

In summary, two overall goals guided this content analysis. First, the definition of sexual consequences (both positive and negative) was expanded to include not only physical consequences but also social and emotional consequences. The hypothesis was that social and emotional consequences would outnumber physical consequences. Second, gender differences in the spirit of the sexual double standard were investigated. Specifically, the sexual double standard might be manifested in the following areas: (a) male characters initiate sex more than female characters, (b) female characters bear the brunt of the negative consequences of sex, (c) male characters reap the positive consequence of sex more than female characters, and (d) negative consequences will be especially likely to occur when female characters initiate sex.

\section{METHOD}

\section{Sample}

To be included in the sample, the television programs had to fit the following criteria: (a) each program had to be $1 \mathrm{~h}$ in length because programs in the 30-minute format are typically of a different genre (e.g., situation comedy, variety show) than the dramas investigated here; (b) the program had to be aired between 8 p.m. and 11 p.m. Eastern Standard Time; (c) the program had to be shown on one of the five broadcast networks (ABC, NBC, CBS, UPN, and WB); and (d) the program had to feature adolescent or college-aged characters. The actual ages of the characters had to be between 12 years, which was thought to be early adolescence and thus the beginning of the development of a sexual identity, and 22 years, which was thought to be the end of late adolescence. Around this age, sexual identities were thought to be relatively stable. $^{4}$

\footnotetext{
${ }^{4}$ The author watched an episode of each of the programs that fit the first three selection criteria (1-h, prime-time, broadcast network) and determined whether any regular members of the cast were between the ages of 12 and 22 years. Because characters often do not explicitly discuss or acknowledge their ages in the episodes, the websites for the television programs were checked to make
}

Programs that feature young characters were chosen for three reasons. First, programming that contains young, attractive characters with whom young viewers are likely to identify will be powerful in influencing viewers' attitudes toward and perceptions of sexuality (Bandura, 1994; Huston, Wartella, \& Donnerstein, 1998). Second, networks such as the WB and UPN explicitly target young viewers with programs that feature mostly adolescent casts, which makes these programs quite popular in the 12-34 age group (Collins, 1998; Freeman, 2000; Keough, 2000; Rathbum, 1999). Third, Kunkel et al. (1999, 2001, 2003) found that shows targeted at adolescents were more likely to portray sexual consequences than were programs that targeted other age groups. Likewise, dramas and soap operas portray sexuality as "high drama," fraught with punishment and pain (Smith, 1991). Thus, to obtain the greatest variation in the types of sexual consequences coded, a sample that was likely to contain a relatively large number of sexual consequences was chosen.

Two waves of episodes were collected for this analysis for a total of 84 episodes (42 episodes per wave). In the Wave 1 sample, programs that appeared between April 16 and May 11, 2000 (4 weeks) were included. A matched sample was collected between October 16 and November 10, 2000 (4 weeks). Two waves of episodes were included to enhance the representativeness of the sample. For example, some programs that aired during the spring of 2000 (e.g., Beverly Hills, 90210 and Party of Five) did not air during the fall of 2000; likewise, some new programs premiered during the fall of 2000 (e.g., Gilmore Girls and Dark Angel). Thus, including both waves of episodes increased the diversity of programs in the sample. It should be noted that both waves of episodes included 2 weeks of sweeps episodes and 2 weeks of nonsweeps episodes. Originally, this was done to test for differences in the portrayal and frequency of sexuality between sweeps and nonsweeps time periods. However, because that was not the goal of the current analysis, those results are not reported here.

The sampling strategy was to include all episodes of a program that occurred during the selected sampling periods. When possible, four episodes per wave were included in the sample. However, because of a variety of circumstances, including scheduling changes, emergency newsbreaks, preemptions, and

sure that at least one character was between the ages of 12 and 22. After the programs were collected, the age of the characters in the sample was coded (Scott's pi $=.94$ ). 
cancellations from the networks, some programs had fewer than four episodes and one program had more than four episodes. ${ }^{5}$

Consecutive episodes were sampled because it was important to follow storylines that continue between episodes. It was found that a sexual transgression in one episode had repercussions for several subsequent episodes; thus, analyzing consecutive episodes was more desirable than analyzing randomly selected episodes.

\section{Coding System}

\section{Units of Analysis}

The programs were coded on two levels: scenes and sexual references. The episodes were coded into scenes, which were defined as exchanges that occurred in a single location with one set of participants present without interruption by time, changes in participants or locations, or commercial breaks (Greenberg \& Busselle, 1996). At this level, coders determined if the scene contained a sexual reference. If a scene contained a sexual reference, it was examined with a more detailed set of coding procedures about type and context. A sexual reference was defined as a depiction of dialogue or behavior that involved sexuality, sexual suggestiveness, sexual activities, or sexual relationships (Kunkel et al., 1999). This definition did not include references to love, romance, or romantic (nonsexual) relationships.

Sexual references could take the form of sexual dialogue or sexual behavior. Sexual dialogue referred to a conversational exchange between characters regarding a sexual topic between characters. Sexual dialogue could also constitute a sexual consequence, if the subject of the conversation was a positive or negative outcome of sexuality. However, the sexual dialogue did not have to contain a consequence. As a minimum requirement, the dialogue had to include

\footnotetext{
${ }^{5}$ In Wave 1, the following programs were included in the sample: 7th Heaven (three episodes), Angel (four episodes), Beverly Hills, 90210 (three episodes), Buffy the Vampire Slayer (four episodes), Charmed (six episodes), Dawson's Creek (four episodes), D.C. (two episodes), Felicity (four episodes), Party of Five (four episodes), Popular (four episodes), and Roswell (four episodes). In Wave 2, the following programs were included in the sample: 7th Heaven (four episodes), Angel (three episodes), Boston Public (two episodes), Buffy the Vampire Slayer (four episodes), Charmed (four episodes), Dark Angel (two episodes), Dawson's Creek (four episodes), Felicity (four episodes), Freakylinks (three episodes), Gilmore Girls (four episodes), Once and Again (two episodes), Popular (two episodes), and Roswell (four episodes).
}

a sexual topic. Each new sexual topic discussed in a scene was coded separately; thus, it was possible to have more than one sexual reference per scene. A behavior was coded as sexual if it conveyed a sense of sexual intimacy. Thus, a peck on the cheek or a friendly hug was not coded as a sexual behavior. The gender of the initiator of the sexual dialogue or sexual behavior was coded for each sexual reference. The initiator was defined as the person who started the conversation with the sexual topic or the person who made the first move that resulted in a sexual behavior.

\section{Negative Sexual Consequences}

A negative consequence was conceptualized as an undesirable outcome related to sexuality. The sexual activity for which a person was punished could be dialogue, as would be the case of a character being ostracized for expressing sexual desire verbally, or it could be behavior, as would be the case of a character being ostracized for engaging in a sexual act. The gender of the recipient who bore the brunt of the consequence was coded (man only, woman only, or both man and woman).

Three types of negative consequences were coded: emotional/social, physical, and punitive. A list of possible nonphysical consequences was compiled to code for emotional and social consequences. After pilot testing the coding scheme with three undergraduate coders, it was determined that the original list could be reduced to four consequences that coders could reliably code. Emotional and social consequences were conceptualized to be similar in that they were both nonphysical; thus, they were coded in a combined category. The main difference between the two was that emotional consequences were experienced in isolation from others, and social consequences were typically exacerbated by others in one's social group. Emotional consequences included disappointment (Carroll, Volk, \& Hyde, 1985) and guilt/anxiety (Levinson, Jaccard, \& Beamer, 1995; Tolman, 1999). Social consequences included humiliation (Tolman, 1994, 1999) and rejection (Tolman, 1994). Physical consequences included unwanted pregnancy, contraction of an STD, and physical abuse by a sexual partner. Punitive consequences occurred when characters were literally punished by others for engaging in a sexual act, such as the case when a teacher gave detention to a couple for "making out" in a school hallway. Punitive consequences could come from a parent, school official, or law enforcement official. In some scenes, there were undertones 
of more than one of these negative consequences; thus, the most obvious consequence was coded to avoid double coding a single interaction. For example, if a scene portrayed a character finding out he had contracted an STD and showed him expressing anxiety in the same scene, only the STD-the more manifest consequence-was coded.

\section{Positive Sexual Consequences}

A positive consequence was conceptualized as an instance in which a character reaped manifest benefit from sexuality. Positive consequences were conceptualized to be emotional/social and physical. Emotional/ social consequences included an increase in selfesteem or self-worth (Kunkel et al., 2001; Levinson et al., 1995), expression of closeness, intimacy, and/or affection (Levinson et al., 1995), and pride in the enhancement of one's reputation among others (Kunkel et al., 2001; Levinson et al., 1995). Positive physical consequences included a clear expression of physical satisfaction and intentional pregnancy.

\section{Coding and Reliability}

Three undergraduate coders underwent extensive training to learn how to implement the coding system. The coders practiced on several episodes before coding the actual sample. The reliability results for these practice episodes were not included in the final reliability results. The purpose of the practice coding was to identify and resolve problems with the coding scheme. After the coding scheme was modified on the basis of these practice rounds, the coding of the episodes was independent. Twenty-four percent of the sample ( $N=20$ episodes) was coded by at least two coders and subjected to reliability analyses.

The coders agreed on the unitizing of the episodes into scenes an average of $91.2 \%$ (the range was $77-100 \%$ ) of the time.

Two scene-level variables were relevant to the hypotheses: agreement on whether the scene contained a sexual reference and agreement on whether the scene contained a sexual consequence. Reliability for both variables was satisfactory. Scott's pi (Krippendorff, 1980) for sexual references was .84, and Scott's pi for sexual consequences (positive or negative) was 78 .

The remaining variables were coded on the reference-level of analysis. Reliability analyses for the reference-level variables showed that the average
Scott's pi for these variables across the 20 episodes was .92 ; the range was from .82 to 1.0 . The specific coefficients were adequate: type of negative consequence (.91), type of emotional/social negative consequence (.83), type of physical negative consequence (.97), type of punitive negative consequence (1.0), type of positive consequence (.92), type of emotional/social positive consequence (.92), type of physical positive consequence (1.0), gender of the initiator of the sexual reference (.95), and gender of the recipient of the consequence (.87).

\section{RESULTS}

Although not the primary goal of this project, notation of the frequency of sex in the sample provides perspective on how sexual the programs were. Of the 84 episodes coded, $90.5 \%(N=76)$ contained at least one sexual reference. Sixteen percent $(N=676)$ of the scenes in the sample contained a sexual reference, and on average, there were 7.9 sexual references per hour of programming.

The strategy for hypothesis testing was twofold. Because the data were categorical, it was necessary to use nonparametric tests (Glass \& Hopkins, 1996). Thus, the first step was to conduct chi-square goodness-of-fit tests to determine if the distribution among categories was not equal, as predicted by the hypotheses. Second, for hypotheses that called for pairwise comparisons among distributions with more than two categories, Marascuilo contrasts were used. Marascuilo contrasts allow for pairwise comparisons between categories that consist of proportion data (Glass \& Hopkins, 1996).

Of the 220 negative consequences found in the sample, coders could decide on a primary type of consequence for 212 . Of these cases, $75.0 \%(N=$ 159) were emotional/social, and only $17.5 \%(N=$ 37) were physical. Punitive consequences comprised $7.5 \%(N=16)$ the negative consequences. Thus, as expected, physical consequences were far less common than emotional and social consequences. For the chi-square test, the null hypothesis was that incidents of negative consequences in the sample were evenly distributed among the three categories: emotional/social, physical, and punitive. Because the chi-square statistic was significant, $\chi^{2}(2, N=212)=$ $168.7, p<.001$, it can be concluded the categories of negative consequences were not evenly distributed. As expected, the pairwise comparison showed that the proportion of emotional/social consequences was significantly greater than the proportion of physical 
Table I. Distribution of Social, Emotional, Physical, and Punitive Sexual Consequences

\begin{tabular}{lrr}
\hline & $N$ & $\%$ \\
\hline Emotional/social consequences & & \\
$\quad$ Guilt/anxiety & 42 & 26.4 \\
Rejection & 41 & 25.8 \\
Humiliation & 37 & 23.3 \\
Disappointment & 36 & 22.6 \\
Other & 3 & 1.9 \\
Total & 159 & 100 \\
Physical consequences & & \\
Unwanted pregnancy & 24 & 64.9 \\
Other & 7 & 18.9 \\
Contraction of STD & 4 & 10.8 \\
Physical abuse & 2 & 5.4 \\
Total & 37 & 100 \\
Punitive consequences & & \\
Punishment by school officials & 13 & 81.3 \\
Punishment by law & 2 & 12.5 \\
Punishment by parents & 1 & 6.3 \\
Total & 16 & 100 \\
\hline
\end{tabular}

Note. Due to rounding error, the \%s do not add to 100 .

consequences, $\chi^{2}(2, N=196)=58.1, p<.001$, and the proportion of punitive consequences, $\chi^{2}(2, N=$ $175)=82.6, p<.001$.

Table I presents the data for the types of emotional and social consequences contained in the sample. The emotional/social consequences were evenly distributed among humiliation, rejection, guilt/anxiety, and disappointment. Table I also shows the types of physical and punitive consequences. Of the few physical consequences, unwanted pregnancies were most common, and punishment by school officials or teachers was the most common type of punitive consequence.

A surprising finding was the dearth of positive consequences of sexuality. Of the 676 scenes with a sexual reference, only $4.1 \%(N=28)$ contained a positive consequence. Of these 28 portrayals, $50.0 \%$ $(N=14)$ were social, $35.7 \%(N=10)$ were physical, and $14.3 \%(N=4)$ were emotional. Because of the small number of positive consequences, it was not possible statistically to compare positive emotional and social consequences to positive physical consequences.

There was little difference between the initiation of sexual dialogue by female and male characters; $51.3 \%(N=231)$ of sexual dialogue was initiated by female character and $48.7 \%(N=219)$ was initiated by male characters. On the other hand, $60.4 \%$ $(N=171)$ of the sexual behaviors were initiated by male characters, and $39.6 \%(N=112)$ were initiated by female characters. The chi-square test demonstrated that the proportion of male initiators and that of female initiatiors were not equal, $\chi^{2}(1, N=283)=$ $12.3, p<.001$. Thus, as predicted, male characters initiated sexual behaviors significantly more often than female characters did.

If the programs conform to the sexual double standard, female characters would be more likely than male characters to receive the negative consequences. Of the 220 negative consequences, a primary recipient of the negative consequence could be identified for 210 . Female characters received $44.3 \%(N=93)$ of the negative consequences, and male characters received $34.3 \%(N=72)$. In the remaining $21.4 \%$ $(N=45)$ of the negative consequences, male and female characters shared the consequences. Many of the programs in the sample (e.g., Felicity, Charmed, Buffy the Vampire Slayer) feature female main characters and arguably target a female audience. Thus, if women were disproportionately featured in the programs, it would make sense that female characters disproportionately receive the negative consequences. To control for this alternative explanation, a cross-tabulation was conducted in which the gender of characters in the scene was controlled. Table II shows the results. As would be expected, when only female characters were featured in the scene, they received the majority of the negative consequences, and when only male characters were in the scene, they received the majority

Table II. A Comparison of the Gender of the Character Who Received the Negative Consequence and the Gender of the Characters in the Scene

\begin{tabular}{lcccc}
\hline & $\begin{array}{c}\text { Women received } \\
\text { negative consequence }\end{array}$ & $\begin{array}{c}\text { Men received } \\
\text { negative consequence }\end{array}$ & $\begin{array}{c}\text { Men and women shared } \\
\text { negative consequence }\end{array}$ & Total \\
\hline Women only in scene & $82.6 \%_{\mathrm{a}}(N=19)$ & $4.3 \%_{\mathrm{b}}(N=1)$ & $13.0 \%_{\mathrm{b}}(N=3)$ & $100 \%(N=23)$ \\
Men only in scene & $21.9 \%_{\mathrm{a}}(N=7)$ & $68.8 \%_{\mathrm{b}}(N=22)$ & $9.4 \%_{\mathrm{a}}(N=3)$ & $100 \%(N=32)$ \\
Men and women in scene & $43.2 \%_{\mathrm{a}}(N=67)$ & $31.6 \%_{\mathrm{a}}(N=49)$ & $25.2 \%_{\mathrm{a}}(N=39)$ & $100 \%(N=155)$ \\
Total & $44.3 \%_{\mathrm{a}}(N=93)$ & $34.3 \%_{\mathrm{a}}(N=72)$ & $21.4 \%_{\mathrm{a}}(N=45)$ & $100 \%(N=210)$ \\
\hline
\end{tabular}

Note. The chi-square goodness-of-fit statistic was significant, $\chi^{2}(4, N=210)=32.65, p<.001$. Pairwise comparisons were done using Marascuilo contrasts (Glass \& Hopkins, 1996). Means in the same row that do not share subscripts differ at $p<.05$ 
of the negative consequences. However, most of the scenes that portrayed a negative consequence $(73.8 \%$, $N=155)$ featured both male and female characters. In these scenes, women were still more likely than men to receive negative consequences. The chi-square test showed that the distribution among categories was not equal. However, pairwise comparisons did not demonstrate a significant difference between female characters $(43.2 \%, N=67)$ and male characters receiving the negative consequences $(31.6 \%, N=49)$. This is probably due to the small sample sizes within the cells.

The analogous prediction was that male characters would be more likely than female characters to be rewarded for sexual activities. Again, it was not possible to analyze this possibility statistically because of the surprisingly low number of positive consequences coded in the sample. Of the 28 positive consequences, the pattern predicted by the sexual double standard was not supported: $39.3 \%(N=11)$ benefited female characters only, whereas $25.0 \%(N=$ 7) benefited male characters only. In the remaining $35.8 \%(N=10)$, male and female characters shared the positive consequences. Clearly, no firm conclusions about the trend in these data can be made because of the small number of positive consequences identified.

Also related to the sexual double standard is the notion that morally good women do not initiate sexual activities. If the programs conform to the sexual double standard, a negative consequence will be more likely to be the result of a woman than a man initiating sexual activities. To analyze this possibility, a scene-level analysis was conducted, in which the gender of the initiator of the sexual reference was crosstabulated against whether or not the scene contained a negative consequence. Table III shows the results. The chi-square test showed that the distribution among categories was not equal, and, as expected, the pairwise comparison showed that the scenes were significantly more likely to portray a negative consequence (for women or men) when female characters initiated a sexual reference than when male characters initiated a sexual reference.

\section{DISCUSSION}

A major goal of this study was to explore the posibility that, on television, sexual consequences are more than just physical. If only physical consequences had been coded, as has been the common practice in previous content analyses, then it would have been concluded that only $5.5 \%(N=37)$ of the 676 scenes with a sexual reference contained a consequence. Indeed, this estimate would have been in range with the percentage of "risk and responsibility" themes (4-6\%) found by Kunkel et al. (1999, 2003). In short, the data would have suggested that these programs were relatively free from consequences. However, with the definition of sexual consequences expanded to include emotional, social, and punitive consequences, $32.5 \%(N=220)$ of scenes with a sexual reference contained a negative consequence. Thus, past content analyses that have used a narrow definition of negative consequences have underestimated the occurrence of negative consequences in the portrayal of sexuality on television. To say that television does not portray consequences because it does not portray unwanted pregnancies or STDs does not represent the whole picture of sexual consequences on television. This finding is particularly important because adolescents seem to express more concern about the possible emotional and social pitfalls of sex than they do about the physical pitfalls (Martin, 1996). Thus, future researchers should consider not just the manifest, physical consequences of sexuality, but also the more commonly experienced emotional and social consequences associated with sexuality.

Another goal of the study was to determine if sexuality was portrayed differently for male and female characters. Although the data demonstrated that the proportion of male characters, female characters, and male and female characters who received a negative

Table III. A Scene-Level Comparison of Gender of Initiator and Negative Consequences

\begin{tabular}{lccr}
\hline & Initiation by male character & Initiation by female character & \multicolumn{1}{c}{ Total } \\
\hline No negative consequence & $70.0 \%_{\mathrm{a}}(N=319)$ & $30.0 \%_{\mathrm{b}}(N=137)$ & $100.0 \%(N=456)$ \\
Negative consequence & $40.1 \%_{\mathrm{a}}(N=90)$ & $59.1 \%_{\mathrm{b}}(N=130)$ & $100.0 \%(N=220)$ \\
Total & $60.5 \%_{\mathrm{a}}(N=409)$ & $39.5 \%_{\mathrm{b}}(N=267)$ & $100 \%(N=676)$ \\
\hline
\end{tabular}

Note. The chi-square goodness of-fit-statistic was significant, $\chi^{2}(1, N=676)=7.85, p<.05$. Pairwise comparisons were done using Marascuilo contrasts (Glass \& Hopkins, 1996). Means in the same row that do not share subscripts differ at $p<.05$. 
consequence was not equal, a Marascuilo contrast failed to demonstrate a significant difference between male characters and female characters.

Although the difference between men and women receiving consequences was not statistically significant, young viewers might still learn that it is more appropriate for men than for women to make the sexual "first move." Research shows that girls internalize the belief that "nice" girls and "good" women do not take the initiative in satisfying their sexual desires; they wait for men to make the first move, and, even then, they control and restrict how far the sexual behavior will advance (Tolman, 1994, 1999). The dramas supported this notion in two ways. First, a scene was more likely to end in a negative consequence (to either men or women) when women initiated sex than when men initiated sex. In other words, bad things happened when women took the sexual initiative. This pattern could act as a warning that is relevant to both male and female viewers. Female viewers learn that taking the sexual initiative is dangerous to themselves and others, and male viewers learn that they are not immune to receiving negative consequences when women take the sexual initiative. Second, male characters simply initiated more sexual behaviors than did female characters. Thus, the repetition of men initiating sex might normalize men's sexuality as proactive and women's sexuality as reactive.

Even though almost one-third of the scenes in the sample featured any message about consequences, it is still true that a majority of the scenes did not contain a negative consequence. Thus, it would be tempting to conclude that, on the whole, teen programming is tacitly encouraging of sex because there was no direct message discouraging sex in the majority of the scenes. However, it would be misleading to conclude that a relatively smaller number of consequences would not have an impact on young viewers. Sexual lessons, those references that include a consequence, could be the aspects of the programs most remembered by viewers and thus quite influential. According to social cognitive theory (Bandura, 1994), viewers will attend to and retain information that conveys the functional value of the behavior. Thus, one might predict that the sexual scripts on television that emphasize the functional value of certain sexual behaviors might be more likely to be internalized by the young viewers than depictions of sexuality that do not communicate functional value. For example, the portrayal of a kiss between a male and female character might not be noteworthy per se. However, if a character is in some way punished or rewarded for that kiss, the viewers might be more likely to retain that information and incorporate it into their cognitive scripts.

It is also notable that it was not possible to analyze positive sexual consequences statistically due to the small number of positive consequences coded in this sample. Why were there so few positive consequences and, relatively speaking, such a substantial number of negative consequences? There are several explanations to consider. First, positive consequences might be less obvious to coders than negative consequences. For example, it was easier to code for STDs than to code for clear and visible pleasure that resulted from a sexual act. In fact, some positive consequences of sex, such as maintenance of a relationship, might not be best coded on the scene level, but perhaps on an episode or season level of analysis. Second, teen programming might contain more negative consequences and fewer positive consequences than general-audience television programming because the programs rely on sexual consequences and conflict to build and advance plotlines. Third, from a cultural perspective, adolescents' sexuality is generally considered detrimental, inappropriate, and irresponsible (e.g., Tolman, 1994); thus, television producers and writers might feel pressure from parents and media watch groups to show adolescents' sexuality as painful, conflict-ridden, and full of consequences. Fourth, the portrayals might simply be true to life. Indeed, research shows that early sexual relationships are often accompanied by pain, regret, and insecurity (Martin, 1996), and engaging in early sexual intercourse is predictive of a variety of negative outcomes for adolescents, including, for example, lowered academic achievement (e.g., Schvaneveldt, Miller, Berry, \& Lee, 2001), antisocial behavior (e.g., Bingham \& Crockett, 1996; Tubman, Windle, \& Windle, 1996), and substance abuse (e.g., Tubman et al., 1996). In considering these explanations, it should be noted that the frequency of sexual consequences and the imbalance between positive and negative consequences found in this sample of teen programming cannot be generalized to general-audience television programming or to other genres of television.

Another limitation was related to the sampling of episodes. All episodes that were shown during two 4-week periods were included in the sample. A consequence of this sampling strategy was that programs that showed four consecutive episodes during the sampling periods were given more weight than were programs that showed fewer than four episodes. For example, in both waves, four episodes of 
Dawson's Creek were recorded. Thus, relatively more weight was given to Dawson's Creek than to a program such as Dark Angel, which premiered during the second wave of data collection and only showed two episodes during that time, because of interruptions by the World Series baseball games. The uneven weight given to the programs would be problematic if the goal of this study was to estimate the number of sexual consequences found in the sample and generalize this estimate to all television programs. Indeed, if this were the goal, a more appropriate sampling strategy would have been to obtain a representative sample of all of the episodes in the season for each program. However, this was not considered an appropriate sampling strategy for this study. It was important to follow storylines that continued between episodes because sexual transgressions in one episode often had repercussions for several subsequent episodes.

Future studies on this topic could extend, and improve on, several aspects of this analysis. First, in future content analyses, perhaps with a more qualitative approach, researchers could more carefully analyze themes of the entire episode and connect those themes across different episodes and perhaps different seasons. The current analysis was limited in its focus on the scene and reference level of analysis; thus, sexual consequences were examined on a rather contained level. Second, in future content analyses, researchers could delineate genre differences in the portrayal of sexual consequences. Certainly, sitcoms, music videos, soap operas, and talk shows are qualitatively different from the entertainment television programs analyzed here.

It is hoped that this content analysis will lay the groundwork for research on television effects on sexuality. For example, it is possible that exposure to television that supports the sexual double standard could increase young people's endorsement of the sexual double standard in their own lives. If adolescent girls identify with sexually punished female characters, their own sense of sexual agency and sexual esteem could be reduced, and this, in turn, could disempower them from making healthy sexual decisions. Future media effects research might also investigate how young viewers perceive the portrayal of physical and emotional/social consequences on television. Do they find these portrayals to be sexually discouraging? Do they find one gender to be more at risk for negative consequences than the other? Ultimately, it is possible that exposure to these themes in entertainment television could contribute to the overall endorsement of gender stereotypes.

\section{ACKNOWLEDGMENTS}

The author thanks Kristen Harrison and Kirstie Farrar for advice and comments on an earlier draft. The author also thanks Nathan Bertucci, Dana Linnane, and Melissa Pakula, who coded the sample.

\section{REFERENCES}

Bandura, A. (1994). Social cognitive theory of mass communication. In J. Bryant \& D. Zillman (Eds.), Media effects: Advances in theory and research (pp. 61-90). Hillsdale, NJ: Erlbaum.

Bingham, R., \& Crockett, L. J. (1996). Longitudinal adjustment patterns of boys and girls experiencing early, middle, and late sexual intercourse. Developmental Psychology, 32, 647-658.

Carroll, J. L., Volk, K. D., \& Hyde, J. S. (1985). Differences between males and females in motives for engaging in sexual intercourse. Archives of Sexual Behavior, 14, 131-139.

Carpenter, L. M. (1998). From girls into women: Scripts for sexuality and romance in Seventeen magazine, 1974-1994. Journal of Sex Research, 35, 158-168.

Collins, J. (1998, October 26). The youth brigade. Time, pp. 88-90.

Durham, M. G. (1998). Dilemmas of desire: Representations of adolescent sexuality in two teen magazines. Youth and Society, 29, 369-389.

Fernandez-Collado, C. F., Greenberg, B. S., Korzenny, F., \& Atkin, C. K. (1978). Sexual intimacy and drug use in TV series. Journal of Communication, 28(3), 30-37.

Franzblau, S., Sprafkin, J. N., \& Rubinstein, E. A. (1977). Sex on TV: A content analysis. Journal of Communication, 27(2), 164-170.

Freeman, M. (2000, December 11). Peacock network cleans up during November sweeps. Electronic Media, p. 2.

Glass, G. V., \& Hopkins, K. D. (1996). Statistical methods in education and psychology (3rd ed.). Englewood Cliffs, NJ: PrenticeHall.

Greenberg, B. S., \& Busselle, R. W. (1996). Soap operas and sexual activity: A decade later. Journal of Communication, 46(4), 153160 .

Greenberg, B. S., Stanley, C., Siemicki, M., Heeter, C., Soderman, A., \& Linsangan, R. (1993). Sex content on soaps and primetime television series most viewed by adolescents. In B. S. Greenberg, J. D. Brown, \& N. L. Buerkel-Rothfuss (Eds.), Media, sex, and the adolescent (pp. 29-44). Cresskill, NJ: Hampton Press.

Huston, A. C., Wartella, E., \& Donnerstein, E. (1998). Measuring the effects of sexual content in the media: A report to the Kaiser Family Foundation. Menlo Park, CA: Kaiser Family Foundation.

Jessor, S. L., \& Jessor, R. (1975). Transition from virginity to nonvirginity among youth: A social-psychological study over time. Developmental Psychology, 11, 473-484.

Keough, C. (2000, December 4). Weblets put a big dent in the ratings of major networks. Los Angeles Business Journal, p. 7.

Krippendorff, K. (1980). Content analysis: An introduction to its methodology. Beverly Hills, CA: Sage.

Kunkel, D., Biely, E., Eyal, K., Cope-Farrar, K., Donnerstein, E., \& Fandrich, R. (2003). Sex on TV: A biennial report to the Kaiser Family Foundation. Menlo Park, CA: Kaiser Family Foundation.

Kunkel, D., Cope, K. M., \& Biely, E. (1999). Sexual messages on television: Comparing findings from three studies. Journal of Sex Research, 36, 230-236.

Kunkel, K., Cope, K. M., \& Colvin, C. (1996). Sexual messages on family hour television: Content and context. Menlo Park, CA: Kaiser Family Foundation. 
Kunkel, D., Cope-Farrar, K., Biely, E., Farinola, W. J. M., \& Donnerstein, E. (2001). Sex on TV: A biennial report to the Kaiser Family Foundation. Menlo Park, CA: Kaiser Family Foundation.

Levinson, R. A., Jaccard, J., \& Beamer, L. (1995). Older adolescents' engagement in casual sex: Impact of risk perception and psychosocial motivations. Journal of Youth and Adolescence, 24, 349-364.

MacCorquodale, P. (1989). Gender and sexual behavior. In K. McKinney \& S. Sprecher (Eds.), Human sexuality: The societal and interpersonal context (pp. 91-112). Norwood, NJ: Ablex.

Martin, K. A. (1996). Puberty, sexuality, and the self: Boys and girls at adolescence. New York: Routledge.

Muehlenhard, C. L. (1988). "Nice women" don't say yes and "real men" don't say no: How miscommunication and the double standard can cause sexual problems. Women and Therapy, 7(2/3), 95-108

Rathbum, E. A. (1999, July 5). Stations say the WB's worth it. Broadcasting and Cable, p. 6.

Schvaneveldt, P. L., Miller, B. C., Berry, E. H., \& Lee, T. R. (2001). Academic goals, achievement, and age at first sexual intercourse: Longitudinal, bi-directional influences. Adolescence, 36, 767-787.

Smith, C. (1991). Sex and genre on prime time. Journal of Homosexuality, 21, 119-138.
Sprafkin, J. N., \& Silverman, L. T. (1981). Update: Physically intimate and sexual behavior on prime-time television. Journal of Communication, 31, 34-40.

Tolman, D. L. (1994). Doing desire: Adolescent girls' struggles for/with sexuality. Gender and Society, 8, 324-342.

Tolman, D. L. (1999). Female adolescent sexuality in relational context: Beyond sexual decision-making. In N. G. Johnson, M. C. Roberts, \& J. Worell (Eds.), Beyond appearance: A new look at adolescent girls (pp. 227-246). Washington, DC: American Psychological Association.

Tubman, J. G., Windle, M., \& Windle, R. C. (1996). Cumulative sexual intercourse patterns among middle adolescents: Problem behavior precursors and concurrent health risk behaviors. Journal of Adolescent Health, 18, 182-191.

Truglio, R. T. (1998). Television as a sex educator. In K. Swan, C. Meskill, \& S. DeMaio (Eds.), Social learning from broadcast television (pp. 7-23). Cresskill, NJ: Hampton Press.

Ward, L. M. (1995). Talking about sex: Common themes about sexuality in prime-time television programs children and adolescents view most. Journal of Youth and Adolescence, 24, 595615.

Wray, J., \& Steele, J. R. (2002). Girls in print: Figuring out what it means to be a girl. In J. D. Brown, J. R. Steele, \& K. Walsh-Childers (Eds.), Sexual teens, sexual media: Investigating media's influence on adolescent sexuality (pp. 191-208). Mahwah, NJ: Erlbaum. 